\title{
Simulation of the Thermal Hydraulic Processes in the Horizontal Steam Generator with the Use of the Different Interfacial Friction Correlations
}

\author{
Vladimir Melikhov, ${ }^{1}$ Oleg Melikhov, ${ }^{2}$ Yury Parfenov, ${ }^{2}$ and Alexey Nerovnov ${ }^{2}$ \\ ${ }^{1}$ Thermo-Hydraulics Division, Electrogorsk Research and Engineering Center for Safety of Nuclear Power Plants, \\ Saint Constantine Street 6, Electrogorsk, Moscow 142530, Russia \\ ${ }^{2}$ NPP Division, Moscow Power Engineering Institute, Krasnokazarmennaya Street 14, Moscow 111250, Russia
}

Correspondence should be addressed to Vladimir Melikhov, vladimir.melikhov@erec.ru

Received 31 May 2011; Accepted 5 July 2011

Academic Editor: Iztok Tiselj

Copyright (C) 2011 Vladimir Melikhov et al. This is an open access article distributed under the Creative Commons Attribution License, which permits unrestricted use, distribution, and reproduction in any medium, provided the original work is properly cited.

The horizontal steam generator (SG) is one of specific features of Russian-type pressurized water reactors (VVERs). The main advantages of horizontal steam generator are connected with low steam loads on evaporation surface, simple separation scheme and high circulation ratio. The complex three-dimensional steam-water flows in the steam generator vessel influence significantly the processes of the steam separation, distribution, and deposition of the soluble and nonsoluble impurities and determine the efficiency and reliability of the steam generator operation. The 3D code for simulation of the three-dimensional steam-water flows in the steam generator could be effective tool for design and optimization of the horizontal steam generator. The results of the code calculations are determined mainly by the set of the correlations describing interaction of the steam-water mixture with the inner constructions of the SG and interfacial friction. The results obtained by 3D code STEG with the usage of the different interfacial friction correlations are presented and discussed in the paper. These results are compared with the experimental ones obtained at the experimental test facility PGV-1500 constructed for investigation of the processes in the horizontal steam generator.

\section{Introduction}

The complex three-dimensional steam-water flows in the steam generator vessel influence significantly the processes of the steam separation, distribution, and deposition of the soluble and nonsoluble impurities and determine the efficiency and reliability of the steam generator operation [1]. The computer code for reliable simulation of the three-dimensional steam-water flows in the steam generator volume with complex geometry, inner constructions, and distributed heat sources will be effective tool for design and optimization of the complex heat-exchange equipment similar to the horizontal steam generator.

Up to date, several computer codes were developed for simulation of the three-dimensional thermal hydraulic processes in the complex geometries [2-9]. These codes were based on the methods of the multifluid dynamics [10] with the assumptions that considered medium consists of the several interpenetrative and interacting fluids (in the case of the steam generator, there are two fluids: water and steam). Each fluid is characterized by the volume fraction, density, velocity, and temperature. The equations of mass, momentum, and energy conservation with the terms describing interfacial interaction are derived for each fluid by the standard methods. The terms describing interfacial friction and terms describing interaction of the steam-water mixture with the inner constructions influence significantly the results of the simulation of the flows under consideration.

The development, analysis, and systematization of the interfacial friction correlations were fulfilled during the development of the system thermal-hydraulic codes RELAP5, TRAC, CATHARE, and so on. In this activity, several typical flow patterns of the steam-water mixture were identified (bubble flow, dispersed flow, and so on), and for each pattern, the interfacial friction correlations 


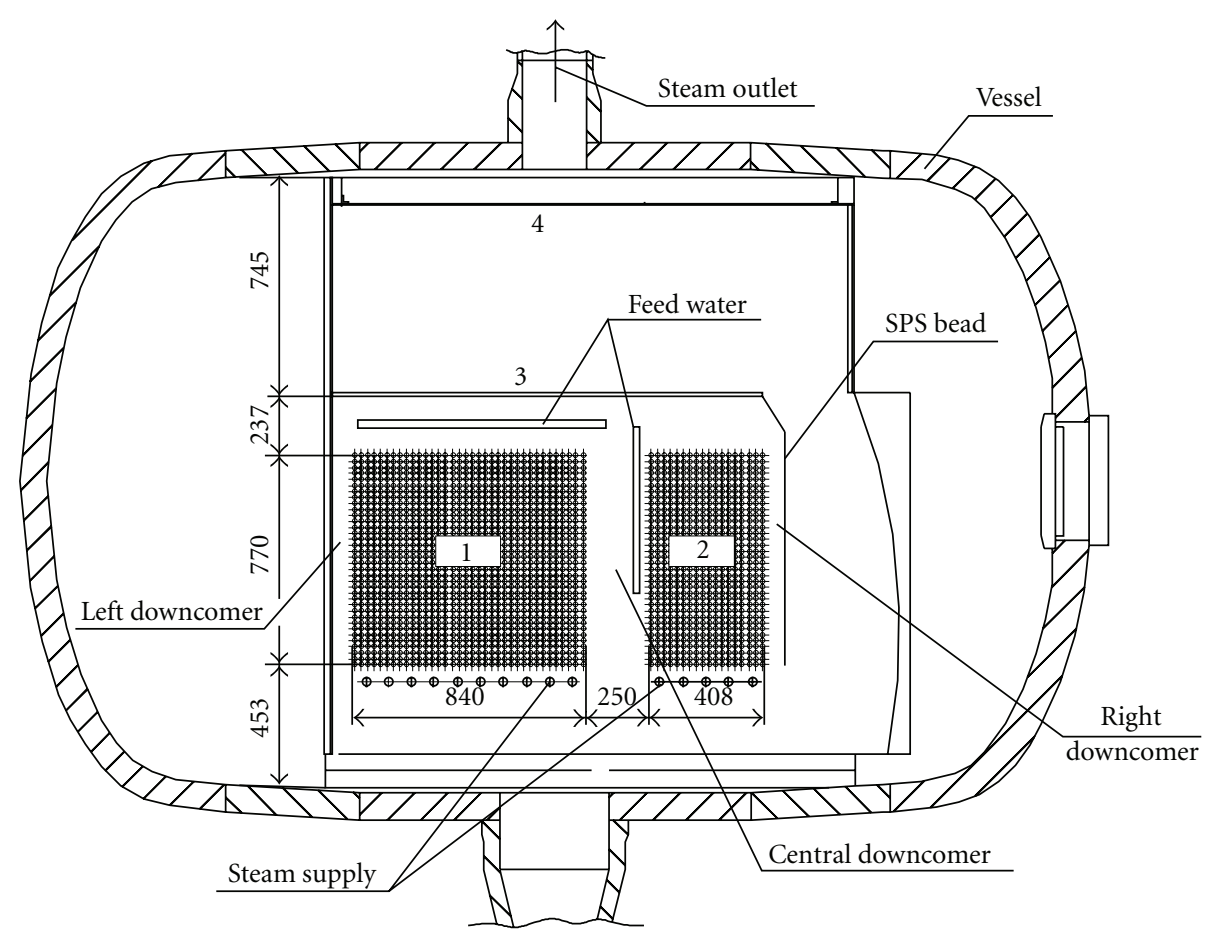

FIGURE 1: General view of experimental model. 1: heated tube bundle, 2: non-heated tube bundle, 3: SPS, and 4: SSPS.

were deriven. It was assumed that the flow pattern for each local point could be one of the patterns identified earlier depending on void fraction, mass flow rate of the steam-water mixture, or another parameter determined by a so-called map of the two-phase flow regimes. A large number of the tests devoted to the investigation of the steam-water flows were analyzed by these thermal-hydraulic codes. These codes demonstrate enough predictive capability of the two-velocity two-temperature models supplemented to the flow regime map. It should be mentioned that the majority of these tests were devoted to the investigation of the flows in the pipes, and the tests were simulated by the one-dimensional thermal-hydraulic codes.

The computer code STEG was developed for numerical simulation of the three-dimensional flows of the steamwater mixture and distribution of the soluble impurities in the steam generator $[11,12]$. The code was validated on the restricted number of data of measurements carried out at natural VVER steam generators in 1980-1990. The recent experimental studies of the horizontal steam generator thermal hydraulics with the large number of measurements [13] formed the experimental data base for more thorough code validation and for analysis of the adequacy of the code correlations.

\section{Brief Description of the Experimental Model}

The PGV-1500 is a horizontal SG developed for new VVER1500 reactor. Previously STEG code was validated in relation to the horizontal SG PGV-1000 of the VVER-1000 reactor.
The geometrical and thermal-hydraulic parameters of PGV1500 significantly differ from the PGV-1000 parameters. In order to validate STEG in relation to the thermal-hydraulic phenomena listed above taking into account parameters of the PGV-1500, the experimental thermal-hydraulic model was constructed in OKB Gidropress (Russian Chief Designer of VVER reactors).

General view of the experimental model is presented in Figure 1. The model is a narrow slice of upper part of horizontal steam generator PGV-1500. The main parts of the model are heated (1) and nonheated (2) tube bundles with in-line arrangement, submerged perforated sheet (SPS) (3) with bead (4) near non-heated tube bundle and steam separation perforated sheet (SSPS) (5). The diameter of the SPS and SSPS orifices and the distances between these orifices are the same as in the reference steam generator PGV-1500. The diameter of the tubes in the tube bundles and the distances between the tubes in the horizontal and vertical direction are the same as in the reference steam generator. The height of the bundles in the model is smaller than the height of the bundles in the reference steam generator. In order to simulate the steam generation in the lower part of the steam generator bundles, steam is supplied under the model tube bundles. The model is installed in the highpressure vessel.

The following thermal-hydraulic parameters were measured at the model:

(1) average void fractions based on hydrostatic method;

(2) collapsed levels above SPS;

(3) pressure differences on SPS and heated tube bundle; 


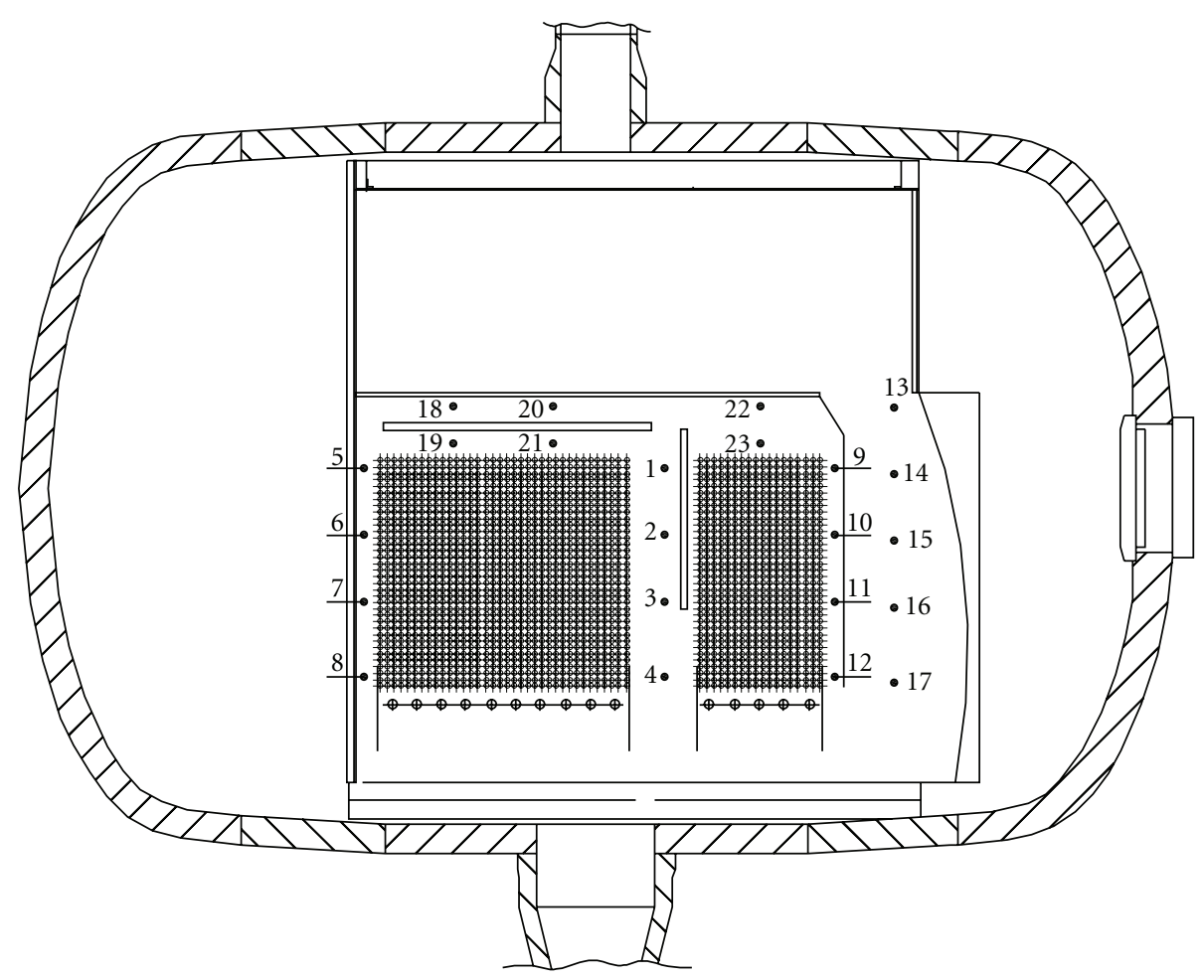

FIgUre 2: Positions of the void fraction measurements.

(4) steam humidity;

(5) flow rate of steam supply;

(6) water temperature.

The accuracy of the pressure differences measurement was $0.5 \%$, and the accuracy of the water temperature measurements was $2.4^{\circ} \mathrm{C}$.

The general scheme of the void fraction measurements is presented in Figure 2. The average value of the void fraction in the certain area of the downcomer was obtained according to the pressure drop between the appropriate points. For example, the average void fraction in the lower area of the left downcomer was obtained according to the pressure drop between the point 8 and 7 , for the central area according to the pressure drop between the points 7 and 6, and for the upper area according to the pressure drop between the points 6 and 5 . The values of the average void fractions in the central, right downcomer, in the area between the SPS bead and SG wall, were obtained by the similar method. The void fractions under the SPS were obtained according to the pressure drop measurements between the points 18 and 19, 20 and 21 , and 22 and 23.

Nine tests were performed at the model. All of them are divided into three cases:

(1) simultaneous steam supply and heating of heated tube bundle;

(2) heating of heated tube bundle without steam supply;

(3) steam supply without heating of heated tube bundle.
More thorough description of the experimental model is presented in $[13,14]$.

\section{Brief Description of the STEG Code}

The mathematical model of the STEG code is based on the methods of the multiphase flow dynamics [10]. Two-velocity two-temperature three-dimensional nonsteady model of steam-water mixture is used. The mass, momentum, and energy conservation equations are formulated for water and steam. The steam generator tube bundle is simulated with the model of the porous media.

The mass conservation equations are

$$
\begin{gathered}
\frac{\partial \alpha_{l} \rho_{l}^{0}}{\partial t}+\frac{\partial \alpha_{l} \rho_{l}^{0} u_{l}}{\partial x}+\frac{\partial \alpha_{l} \rho_{l}^{0} v_{l}}{\partial y}+\frac{\partial \alpha_{l} \rho_{l}^{0} w_{l}}{\partial z}=-\Gamma+M_{l}, \\
\frac{\partial \alpha_{v} \rho_{v}^{0}}{\partial t}+\frac{\partial \alpha_{v} \rho_{v}^{0} u_{v}}{\partial x}+\frac{\partial \alpha_{v} \rho_{v}^{0} v_{v}}{\partial y}+\frac{\partial \alpha_{v} \rho_{v}^{0} w_{v}}{\partial z}=\Gamma+M_{v} .
\end{gathered}
$$

The momentum conservation equations are

$$
\begin{aligned}
\frac{\partial \vec{V}_{l}}{\partial t}+\overrightarrow{V_{l}} \nabla \vec{V}_{l}= & -\frac{1}{\rho_{l}^{0}} \nabla P-\frac{\Gamma^{-}\left(\vec{V}_{v}-\vec{V}_{l}\right)}{\alpha_{l} \rho_{l}^{0}} \\
& +\frac{c_{l v}}{\alpha_{l} \rho_{l}^{0}}\left|\vec{V}_{v}-\vec{V}_{l}\right| \cdot\left(\vec{V}_{v}-\vec{V}_{l}\right) \\
& -\frac{c_{w l}}{\alpha_{l} \rho_{l}^{0}}\left|\vec{V}_{l}\right| \cdot \vec{V}_{l}+\vec{g}+\frac{M_{l}\left(\vec{V}_{l s}-\vec{V}_{l}\right)}{\alpha_{l} \rho_{l}^{0}},
\end{aligned}
$$




$$
\begin{aligned}
\frac{\partial \vec{V}_{v}}{\partial t}+\vec{V}_{v} \nabla \overrightarrow{V_{v}}= & -\frac{1}{\rho_{v}^{0}} \nabla P-\frac{\Gamma^{+}\left(\vec{V}_{v}-\vec{V}_{l}\right)}{\alpha_{v} \rho_{v}^{0}} \\
& -\frac{c_{l v}}{\alpha_{v} \rho_{v}^{0}}\left|\vec{V}_{v}-\vec{V}_{l}\right| \cdot\left(\vec{V}_{v}-\vec{V}_{l}\right) \\
& -\frac{c_{w v}}{\alpha_{v} \rho_{v}^{0}}\left|\overrightarrow{V_{v}}\right| \cdot \vec{V}_{v}+\vec{g} \\
& +\frac{M_{v}\left(\overrightarrow{V_{v s}}-\vec{V}_{v}\right)}{\alpha_{v} \rho_{v}^{0}},
\end{aligned}
$$

where

$$
\Gamma^{+}=\left\{\begin{array}{l}
\Gamma \text { if } \Gamma>0, \\
0 \text { if } \Gamma \leq 0,
\end{array} ; \quad \Gamma^{-}= \begin{cases}0 & \text { if } \Gamma>0 \\
\Gamma & \text { if } \Gamma \leq 0 .\end{cases}\right.
$$

The energy conservation equations are

$$
\begin{aligned}
& \frac{\partial \alpha_{l} \rho_{l}^{0} i_{l}}{\partial t}+\frac{\partial\left(\alpha_{l} \rho_{l}^{0} i_{l} u_{l}\right)}{\partial x}+\frac{\partial\left(\alpha_{l} \rho_{l}^{0} i_{l} v_{l}\right)}{\partial y}+\frac{\partial\left(\alpha_{l} \rho_{l}^{0} i_{l} w_{l}\right)}{\partial z} \\
& =\alpha_{l} \frac{d P}{d t}+q_{s l}-\Gamma i_{s l}+q_{w l}+M_{l} H_{l} \\
& \frac{\partial \alpha_{v} \rho_{v}^{0} i_{v}}{\partial t}+\frac{\partial\left(\alpha_{v} \rho_{v}^{0} i_{v} u_{v}\right)}{\partial x}+\frac{\partial\left(\alpha_{v} \rho_{v}^{0} i_{v} v_{v}\right)}{\partial y}+\frac{\partial\left(\alpha_{v} \rho_{v}^{0} i_{v} w_{v}\right)}{\partial z} \\
& =\alpha_{v} \frac{d P}{d t}+q_{s v}+\Gamma i_{s v}+q_{w v}+M_{v} H_{v}
\end{aligned}
$$

where subscripts $l, v$ appropriates to water and steam, respectively, $\alpha$ is volume fraction, $\rho^{0}$ is density, $\vec{V}(u, v, w)$ : velocity, $i$ is enthalpy, $P$ is pressure, $\Gamma$ is interfacial masstransfer rate, $M$ is mass source term, $c_{l v}$ is interfacial friction coefficient, $c_{w}$ is tubes wall friction coefficient, $\overrightarrow{V_{l s}}$ is velocity of the water source, $\overrightarrow{V_{v s}}$ is velocity of the steam source, $q_{w}$ is wall heat-transfer rate, $q_{s}$ is interfacial heat transfer, $H_{l}$ is enthalpy of the water source, $H_{v}$ is enthalpy of the steam source, $i_{s l}$ is water saturation enthalpy, $i_{s v}$ is steam saturation enthalpy.

Constitutive relations for interfacial friction and heat exchange are based on the map of the flow regimes. The heat flux from primary to secondary one is assigned as boundary condition. The simulation of the friction of the steam-water flow with the tube bundles was based on the correlations [15]. This friction was divided among the water and steam according to their volume fractions. The finite-difference semi-implicit numerical method is used to integrate the governing equations. More thorough description of the STEG code is presented in $[7,8,12]$.

\section{Numerical Simulation of the Experimental Regime with STEG}

The paper contains analysis of experimental regime in which the steam-water flow was induced by the steam supply under the tube bundles of the model. The calculation grid $42 \times 1 \times$ 46 (number of control volumes along the length, width, and

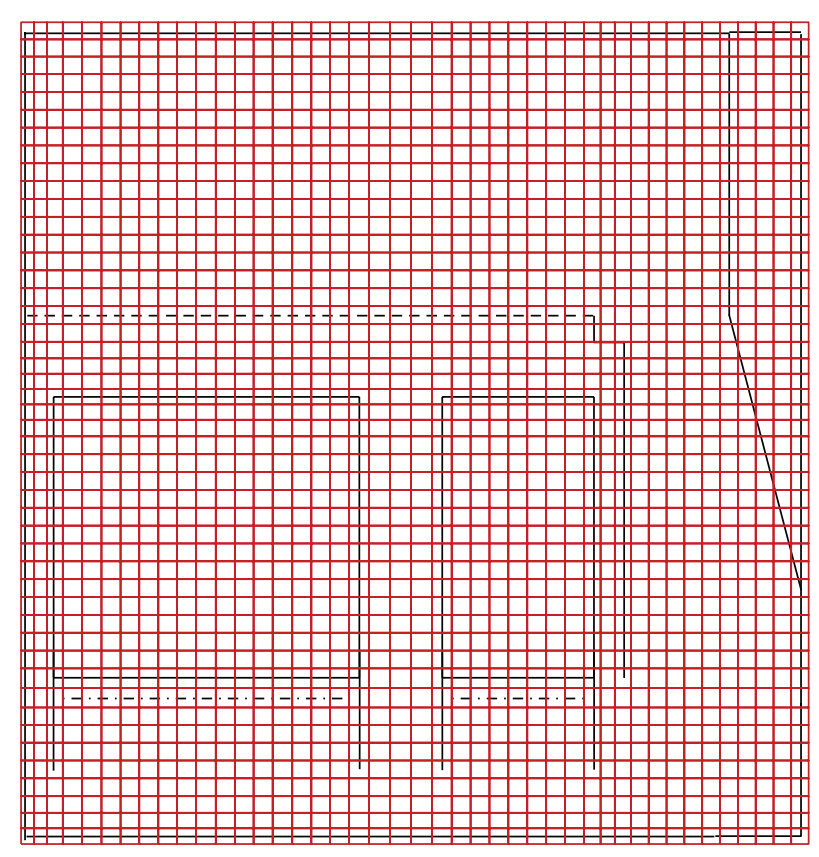

Figure 3: Nodalization of the SG model.

height of the model) was used. It should be mentioned that in fact 2D nodalization scheme was used for simulation, because thermal-hydraulic processes along the width of the narrow slice model of the PGV-1500 were negligible. This grid was chosen on the basis of the experience of the similar calculations. Nodalization of the SG model is presented in Figure 3.

Two comparative calculations were carried out. In the first one, the interfacial friction was described by the TRAC correlations [2], in the second one, with the help of the correlations [16].

TRAC interfacial friction coefficient [2] is chosen based on the flow regime: bubbly-slug, annular-mist, stratified flow, and the transitions among them. The key parameters in the determining flow regime are the local total mass flux and the void fraction. The interfacial friction force per unit volume for bubbly-slug flow regime is expressed in the form

$$
\overrightarrow{F_{21}}=\frac{3}{4} \alpha_{v} \rho_{l} \frac{C_{D}}{D_{p}} P_{s}\left|\vec{V}_{v}-\vec{V}_{l}\right| \cdot\left(\vec{V}_{v}-\vec{V}_{l}\right),
$$

where $C_{D}$ is interfacial friction coefficient, $D_{p}$ is bubble diameter, and $P_{s}$ is profile slip factor.

The interfacial friction coefficient $C_{D}$ is defined as follows:

$$
C_{D}=240 \quad \text { if } \operatorname{Re}<0.1031
$$

$$
\begin{gathered}
C_{D}=\frac{24}{\operatorname{Re}}\left(1.0+0.15 \mathrm{Re}^{0.687}\right) \quad \text { if } 0.1031<\operatorname{Re}<989.0 \\
C_{D}=0.44 \quad \text { if } \operatorname{Re}>989.0
\end{gathered}
$$

where Re is the Reynolds number. The bubble diameter is defined as a function of the Laplace coefficient and the channel hydraulic diameter. 
The profile slip factor is included to account for the migration of bubbles toward the higher-velocity region of the channel. The profile slip factor is defined as

$$
P_{S}=\frac{\left(C_{1} V_{v}-C_{0} V_{l}\right)^{2}}{\left(V_{r}\right)^{2}},
$$

for

$$
\begin{gathered}
C_{0}=1.2-0.2 \sqrt{\frac{\rho_{v}^{0}}{\rho_{l}^{0}}}, \\
C_{1}=\frac{1.0-C_{0} \alpha_{v}}{1.0-\alpha_{v}},
\end{gathered}
$$

where $V_{r}$ is the relative velocity.

In the annular-mist flow regime, the total interfacial drag force is assumed to be a superposition of the separate drag forces caused by the entrained droplets and the annular film

$$
\overrightarrow{F_{21}}=\overrightarrow{F_{\text {id }}}+\overrightarrow{F_{\text {ia }}} \text {, }
$$

where $\overrightarrow{F_{\mathrm{id}}}$ and $\overrightarrow{F_{\mathrm{ia}}}$ represent the drag forces caused by the droplet field and the annular film, respectively.

The interfacial friction force caused by the annular film is calculated as

$$
\left|\overrightarrow{F_{\mathrm{ia}}}\right|=a_{\mathrm{if}} \tau_{f},
$$

where $\tau_{f}$ is the interfacial shear. The interfacial area per unit volume $a_{\text {if }}$ is

$$
a_{\mathrm{if}}=\frac{4 C_{\mathrm{an}}}{D} \sqrt{\frac{\alpha_{v}}{1-\alpha_{d}}},
$$

where $C_{\mathrm{an}}$ is a roughness parameter to account for waviness in the film. In the above equation, the area fraction of the droplets $\alpha_{d}$ is calculated as the ratio of the water and steam superficial velocities $\left(j_{l}\right.$ and $\left.j_{v}\right)$ multiplied by the entrainment $E$

$$
\alpha_{d}=\frac{j_{l}}{j_{v}} E
$$

The entrainment $E$ in turn is based on the correlation of Kataoka and Ishii

$$
E=\tanh \left(7.25 \cdot 10^{-7} \mathrm{We}_{d}^{1.25} \mathrm{Re}_{l}^{0.25}\right),
$$

$\mathrm{We}_{d}$ is the droplet Weber number, $\mathrm{Re}_{l}$ is the liquid Reynolds number.

The shear force $\tau_{f}$ is calculated from

$$
\tau_{f}=0.5 f_{i} \rho_{c}\left(V_{v}-V_{l}\right)^{2},
$$

where $\rho_{c}$ is the density of the steam/droplet core and $f_{i}$ is the interfacial friction factor.

The interfacial friction force caused by the entrained droplet field is calculated as

$$
\begin{gathered}
\left|\overrightarrow{F_{\mathrm{id}}}\right|=a_{i}\left[\frac{C_{d}}{4} \frac{r_{\mathrm{sm}}}{r_{d}} \frac{\rho_{v}\left(V_{v}-V_{d}\right)^{2}}{2}\right], \\
a_{i}=\frac{\alpha_{v}}{1-\alpha_{d}}\left(\frac{3 \alpha_{d}}{r_{\mathrm{sm}}}\right) .
\end{gathered}
$$

In the above equations, $C_{D}$ is the droplet friction coefficient, $r_{\text {sm }}$ is the Sauter mean radius, $r_{d}$ is the droplet radius, $V_{d}$ is the droplet velocity, and $\alpha_{d}$ is the area fraction of the droplet (as defined above). The droplet friction coefficient is estimated as

$$
C_{D}=\frac{24}{\operatorname{Re}_{d}}\left(1,0+0.1 \operatorname{Re}_{d}^{0.75}\right),
$$

where $\mathrm{Re}_{d}$ is the droplet Reynolds number.

In the transitions among the regimes, the interfacial drag coefficient is calculated as a weighted average of appropriate drag coefficients. Detailed description of the TRAC model is presented in [2].

A set of two gas-liquid interfacial friction correlations was proposed in [16] for application to steam-water flows across tube bundles. The interfacial friction force per unit volume is expressed in the form

$$
\overrightarrow{F_{21}}=\frac{3}{4} \alpha_{v} \rho_{l} \frac{C_{D}}{D_{p}}\left|\vec{V}_{v}-\vec{V}_{l}\right| \cdot\left(\vec{V}_{v}-\vec{V}_{l}\right) .
$$

For $\alpha_{v} \leq 0.3$, which correspond to bubbly flow, the first proposed correlation for the ratio of the interfacial drag coefficient $C_{D}$ to the dispersed bubble diameter $D_{p}$ is based on the modified Ishii and Zuber correlation [17]

$$
\frac{C_{D}}{D_{p}}=0,267\left(\frac{g \Delta \rho}{\sigma}\right)^{1 / 2}\left\{\frac{1+17.67 f(\varphi)^{6 / 7}}{18.67 f(\varphi)}\right\}^{2},
$$

where

$$
f(\varphi)=(1-\varphi)^{1,5} .
$$

For $\alpha_{v}>0.3$, which correspond to churn-turbulent flow, a new correlation is proposed with the same functional form, as the CATHARE code correlation [18],

$$
\frac{C_{D}}{D_{p}}=1,487\left(\frac{g \Delta \rho}{\sigma}\right)^{1 / 2}(1-\varphi)^{3}(1-0,75 \varphi)^{2} .
$$

The oscillating behavior of the thermal hydraulic parameters was observed in the experiment. The average value of the void fraction, the difference between maximum and minimum values of the void fraction, and standard deviation of the measurement were presented in the experimental report for each void fraction measurement. Unfortunately, time dependencies of the experimental void fractions were not presented in the report. It should be mentioned that the difference between maximum and minimum values of the void fraction for some measurements was comparable with the average value of the void fraction. The oscillating behavior of the void fractions was observed in the simulation too. As an example, the value of the void fraction in the upper part of the central downcomer is presented in Figure 4 which was obtained in the calculation with the use of the TRAC correlations (5)-(17). The presented value is already averaged in space in the area among points 1 and 2 (Figure 2). The calculation was carried out for 50 seconds. Up to this time, the behavior of all void fraction dependencies could be 
characterized as quasi-steady-state oscillations near average value. The period of time from 40 to 50 seconds was used for averaging the value in time.

At first, let us consider the steam-water flow pattern observed in the experiment. In the area between tube bundles and submerged perforated sheet, the void fraction $\varphi$ was in the range 0.3-0.5. In the upper part of the central downcomer, the void fraction was approximately 0.3 , while in another part of the downcomer, lower than 0.1 .

In the upper and lower parts of the left downcomer, the void fraction was $0.25-0.3$. In the central part of this downcomer this parameter was lower than 0.1 . In the central and upper part of the right downcomer the void fraction was $0.15-0.2$, and in the lower parts it was lower than 0.1 .

In the area between the SPS bead and SG wall practically only water was observed $(\varphi<0.03)$. In the upper part of this area, the void fraction was 0.36 .

The collapsed level above the SPS was $0.13 \mathrm{~m}$ above the left tube bundle, and $0.124 \mathrm{~m}$ above the right one.

Thus, large amount of water in the downcomers was observed in this experimental regime. In the area between the SPS bead and SG wall, only water was observed.

The comparison of the calculated and experimental void fractions in the central downcomer is presented in the Figure 5. It could be seen that the calculation results obtained with the use of the interfacial friction model (18)-(21) are worse than the results obtained with the use of the model (5)-(17).

The comparison of the calculated and experimental void fractions in the left downcomer is presented in Figure 6. As in the case of the central downcomer, the calculation results obtained with the use of the interfacial friction model (18)(21) are worse than the results obtained with the use of the model (5)-(17).

The comparison of the calculated and experimental void fractions in the right downcomer is presented in Figure 7. As in the case of the central and left downcomer, the calculation results obtained with the use of the interfacial friction model (18)-(21) are worse than the results obtained with the use of the model (5)-(17).

The comparison of the calculated and experimental void fractions in the area between the SPS bead and SG wall is presented in the Figure 8 . The calculation results obtained with the use of the interfacial friction model (5)-(17) are in a good agreement with experimental ones, while use of the model (18)-(21) leads to qualitatively incorrect results (in this calculation, the steam-water mixture is observed in the area between the SPS bead and SG wall).

The comparison of the calculated and experimental void fractions under the SPS is presented in Figure 9. It could be seen, that the calculation results obtained with the use of the interfacial friction model (18)-(21) are worse than the results obtained with the use of the model (5)-(17).

The comparison of the calculated and experimental collapsed level above SPS is presented in Table 1. The same trend is observed-the use of the model (18)-(21) leads to worse results.

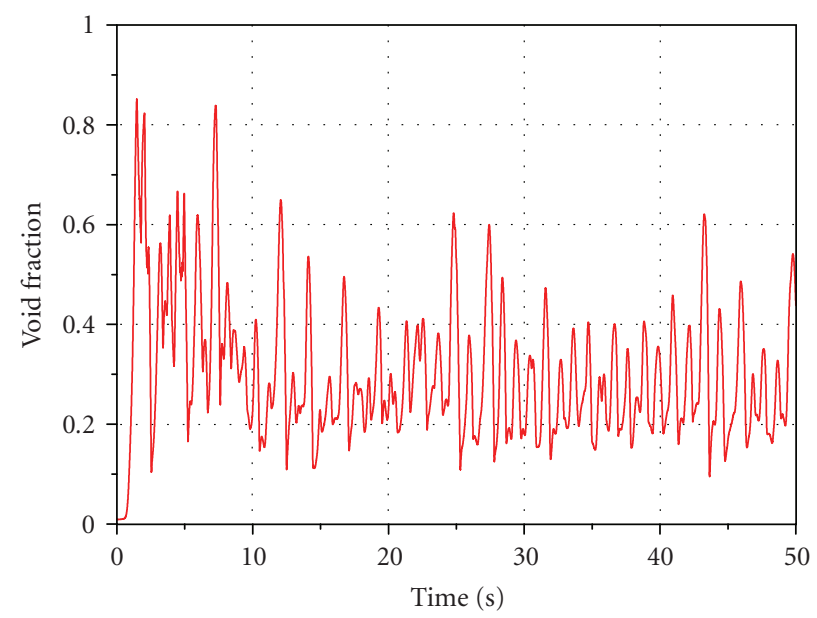

FIGURE 4: Calculated void fraction in the upper part of the central downcomer (among points 1 and 2).

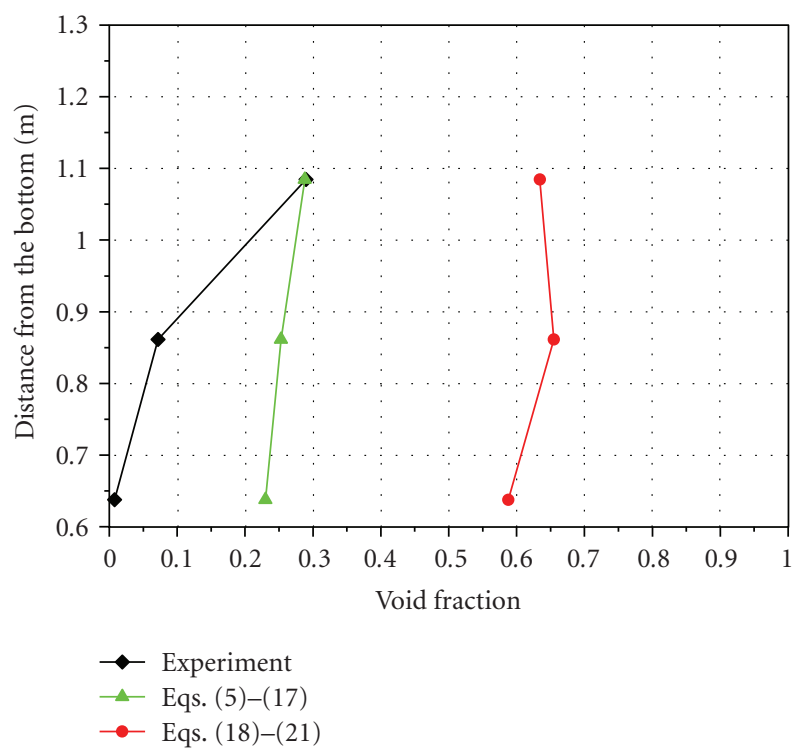

Figure 5: Void fraction profile along height of the central downcomer in the experiment and in the calculations with the use of the models (5)-(17) and (18)-(21).

The results presented above are illustrated by twodimensional distributions of the void fractions in Figure 10. In the calculation with the use of the correlations (5)-(17) the void fraction in the tube bundles is significantly higher than in the downcomers. In the area between SPS bead and SG wall the void fraction is very low. The calculation results obtained with the use of the correlations (5)-(17) are in a good qualitative agreement with experimental ones.

The calculation results obtained with the use of the correlations (18)-(21) significantly differ from the experimental results. The void fraction distribution is practically uniform in the model except lower section, while in the experiment this parameter was significantly different in the different areas of the facility. 


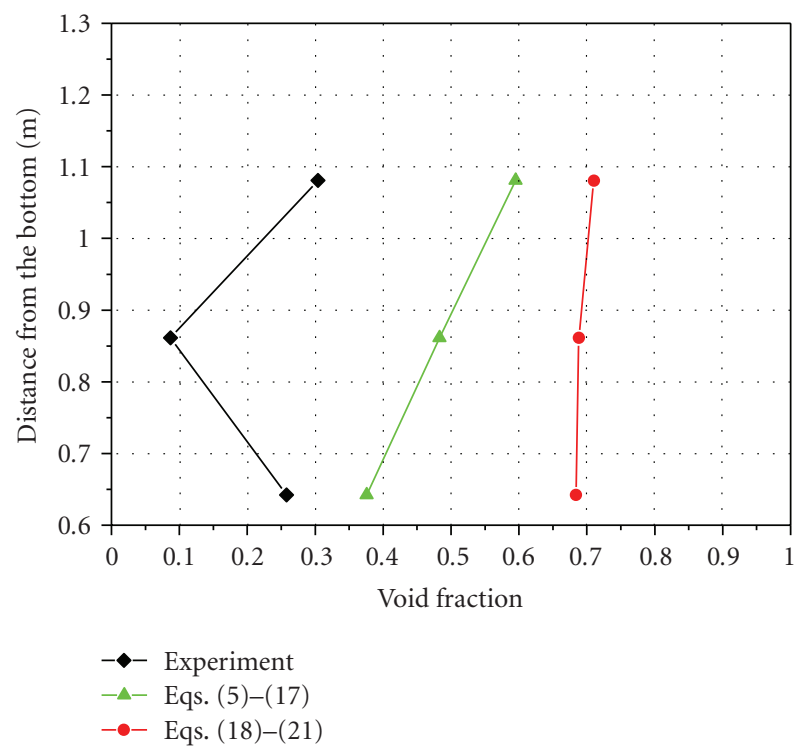

Figure 6: Void fraction profile along height of the left downcomer in the experiment and in the calculations with the use of the models (5)-(17) and (18)-(21).

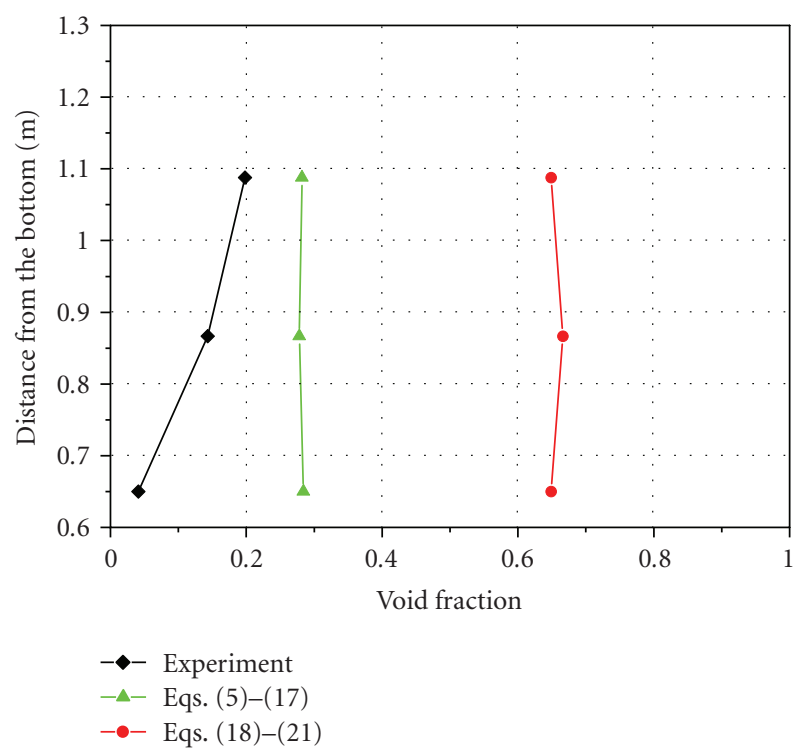

Figure 7: Void fraction profile along height of the right downcomer in the experiment and in the calculations with the use of the models (5)-(17) and (18)-(21).

TABLE 1: Collapsed levels above SPS, m.

\begin{tabular}{lccc}
\hline Bundle & Experiment & $\begin{array}{c}\text { Calculation with Calculation with } \\
(5)-(17)\end{array}$ & $\begin{array}{c}(18)-(21) \\
\text { Left }\end{array}$ \\
Right & 0.13 & 0.11 & 0.27 \\
\hline
\end{tabular}

\section{Conclusions}

(1) The calculations of the experimental regime carried out at the model of the horizontal steam generator

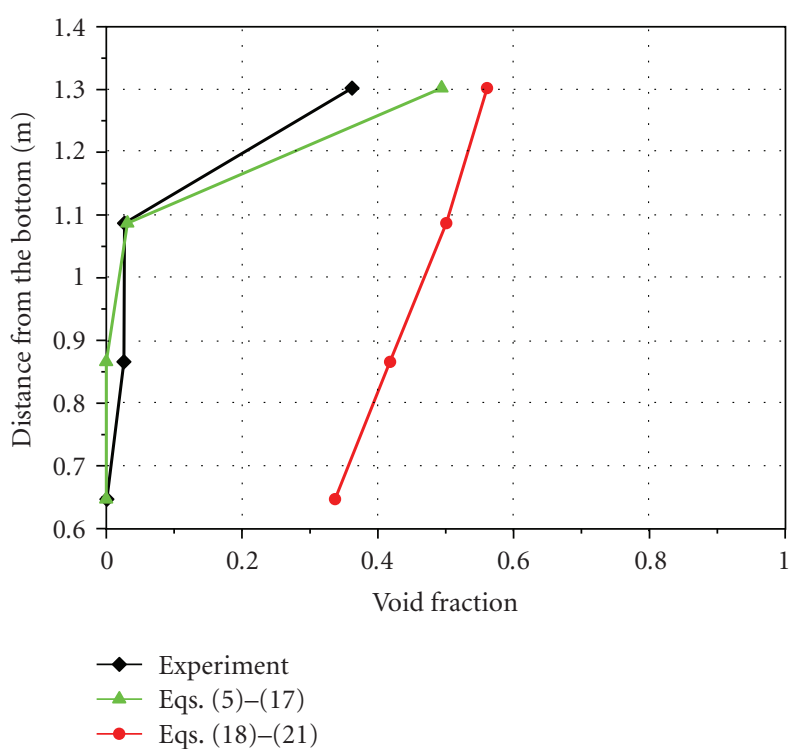

Figure 8: Void fraction profile along height of the area between the SPS bead and SG wall in the experiment and in the calculations with the use of the models (5)-(17) and (18)-(21).

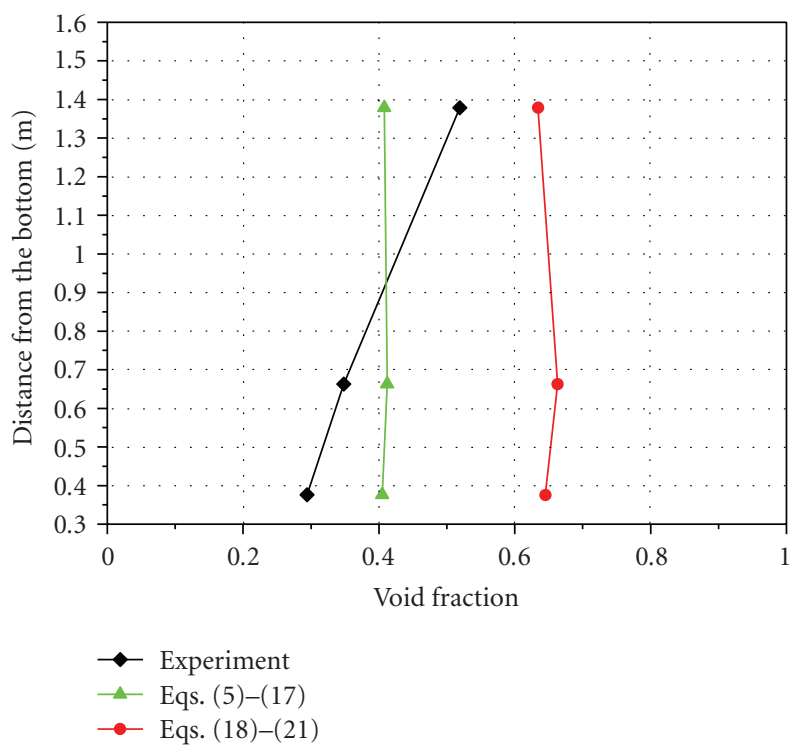

FIGURE 9: Void fraction profile along the width of the SG model in the area under the SPS in the experiment and in the calculations with the use of the models (5)-(17) and (18)-(21).

PGV-1500 [13, 14] were fulfilled with 3D thermal hydraulic code STEG with the use of the interfacial friction correlations (18)-(21) and TRAC interfacial friction correlations (5)-(17).

(2) The results obtained with the TRAC correlations (5)(17) are in a satisfactory agreement with the experimental ones, while calculation results obtained with (18)-(21) significantly differ from the experimental ones. 


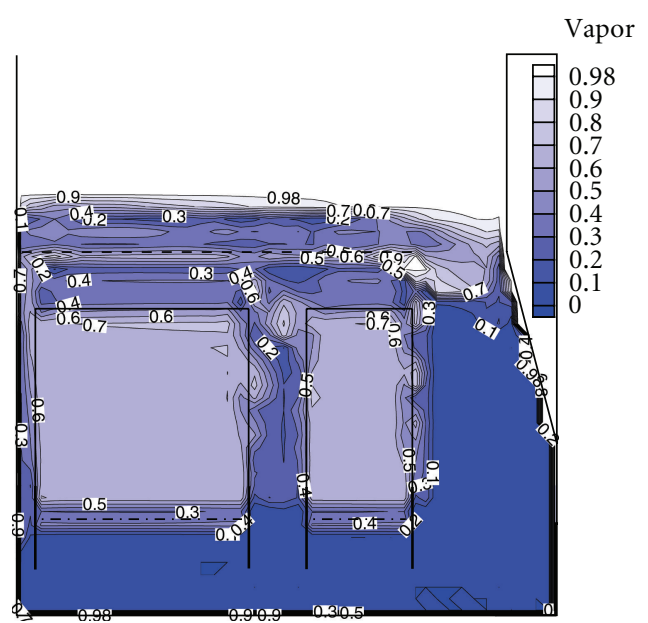

(a)

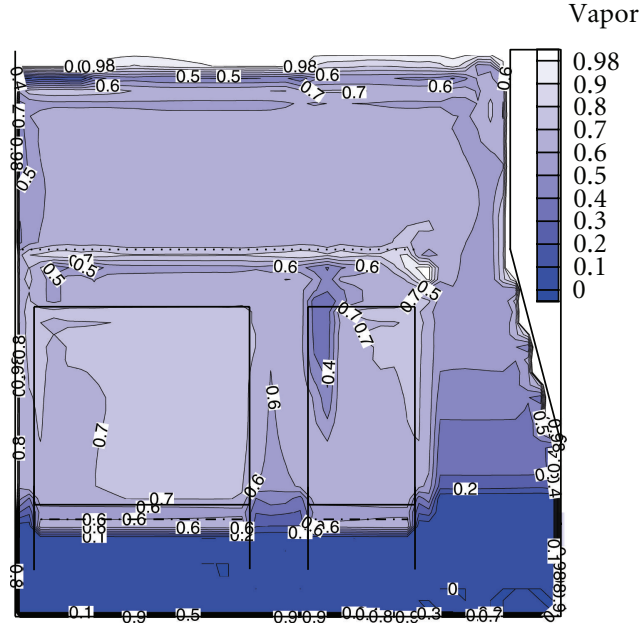

(b)

FIgURE 10: (a) Void fraction distribution in the calculations with the use of the model (5)-(17), (b) Void fraction distribution in the calculations with the use of the model (18)-(21).

\section{Nomenclature}

\section{Latin}

\begin{tabular}{|c|c|}
\hline$a_{\mathrm{if}}:$ & {$\left[\mathrm{m}^{-1}\right]$ Interfacial area per unit volume } \\
\hline$C_{\text {an }}:$ & $\begin{array}{l}{[-] \text { Roughness parameter to account for }} \\
\text { waviness in the film }\end{array}$ \\
\hline$C_{D}:$ & [ - ] Interfacial friction coefficient \\
\hline$C_{d}:$ & [ - ] Droplet friction coefficient \\
\hline$c_{l v}:$ & {$\left[\mathrm{kg} / \mathrm{m}^{4}\right]$ Interfacial friction coefficient } \\
\hline$c_{w}:$ & {$\left[\mathrm{kg} / \mathrm{m}^{4}\right]$ Tubes wall friction coefficient } \\
\hline$D_{p}:$ & {$[\mathrm{m}]$ Bubble diameter } \\
\hline$E:$ & [ - ] Entrainment \\
\hline $\overrightarrow{F_{21}}$ : & $\begin{array}{l}{\left[\mathrm{N} / \mathrm{m}^{3}\right] \text { Interfacial friction force per unit }} \\
\text { volume }\end{array}$ \\
\hline $\overrightarrow{F_{\mathrm{id}}}$ & $\begin{array}{l}{\left[\mathrm{N} / \mathrm{m}^{3}\right] \text { Drag forces caused by the droplet }} \\
\text { field }\end{array}$ \\
\hline $\overrightarrow{F_{\mathrm{ia}}}$ & $\begin{array}{l}{\left[\mathrm{N} / \mathrm{m}^{3}\right] \text { Drag forces caused by the annular }} \\
\text { film }\end{array}$ \\
\hline$f_{i}:$ & [ - ] interfacial friction factor \\
\hline$g:$ & {$\left[\mathrm{m} / \mathrm{s}^{2}\right]$ Gravitational constant } \\
\hline$H_{l}$ : & {$[\mathrm{J} / \mathrm{kg}]$ Enthalpy of the water source } \\
\hline$H_{v}:$ & {$[\mathrm{J} / \mathrm{kg}]$ Enthalpy of the steam source } \\
\hline$i:$ & {$[\mathrm{J} / \mathrm{kg}]$ Enthalpy } \\
\hline$i_{\mathrm{sl}}:$ & {$[\mathrm{J} / \mathrm{kg}]$ Water saturation enthalpy } \\
\hline$i_{\mathrm{sv}}:$ & {$[\mathrm{J} / \mathrm{kg}]$ Steam saturation enthalpy } \\
\hline$j_{l}:$ & [m/s] Water superficial velocity \\
\hline$j_{v}:$ & {$[\mathrm{m} / \mathrm{s}]$ Steam superficial velocity } \\
\hline$\vec{V}(u, v, w):$ & {$[\mathrm{m} / \mathrm{s}]$ Velocity } \\
\hline$P:$ & {$[\mathrm{Pa}]$ Pressure } \\
\hline M: & {$\left[\mathrm{kg} / \mathrm{m}^{3} \mathrm{~s}\right]$ Mass source term } \\
\hline$\vec{V}_{\mathrm{ls}}:$ & {$[\mathrm{m} / \mathrm{s}]$ Velocity of the water source } \\
\hline$\vec{V}_{\mathrm{vs}}:$ & {$[\mathrm{m} / \mathrm{s}]$ Velocity of the steam source } \\
\hline$q_{w}:$ & {$\left[\mathrm{J} / \mathrm{m}^{3} \mathrm{~s}\right]$ Wall heat-transfer rate } \\
\hline$q_{s}:$ & {$\left[\mathrm{J} / \mathrm{m}^{3} \mathrm{~s}\right]$ Interfacial heat transfer } \\
\hline$P_{s}:$ & [ - ] Profile slip factor \\
\hline
\end{tabular}

$r_{d}:[\mathrm{m}]$ Droplet radius

$r_{\mathrm{sm}}:[\mathrm{m}]$ Sauter mean radius

Re: [ - ] Reynolds number

$V_{d}:[\mathrm{m} / \mathrm{s}]$ Droplet velocity

$V_{r}:[\mathrm{m} / \mathrm{s}]$ Relative velocity

We: [ - ] Weber number.

Greek

$\Gamma:\left[\mathrm{kg} / \mathrm{m}^{3} \mathrm{~s}\right]$ Interfacial mass-transfer rate

$\alpha_{d}:[-]$ Area fraction of the droplets

$\alpha: \quad[-]$ Volume fraction

$\rho^{0}:\left[\mathrm{kg} / \mathrm{m}^{3}\right]$ Density

$\rho_{c}:\left[\mathrm{kg} / \mathrm{m}^{3}\right]$ Density of the steam/droplet core

$\sigma:[\mathrm{N} / \mathrm{m}]$ Surface tension

$\tau_{f}:\left[\mathrm{N} / \mathrm{m}^{2}\right]$ Interfacial shear

$\varphi:$ [ - ] Void fraction.

\section{Subscript}

l: Liquid

$v$ : Steam

$d$ : Droplet.

\section{Abbreviation}

SG: Steam generator

STEG: 3D thermal hydraulic code

SPS: Submerged perforated sheet

SSPS: Steam separation perforated sheet

VVER: Water cooled water moderator energy reactor.

\section{Acknowledgments}

This research was supported in the frame of the Russian Federal Target Program "Scientific and scientific-pedagogical personnel of innovative Russia" in 2009-2013 by the State 
Contract no. $\Pi 491$ of 13.05 .2010 , by the State Contract no. $\Pi 1091$ of 31.05.2010, and by Russian Foundation for Basic Research, RFBR Projects 10-08-00373-a, 10-08-00086-a, and 09-08-00962-a, 09-08-00959-a.

\section{References}

[1] N. B. Trunov, S. A. Logvinov, and Y. G. Dragunov, Hydrodynamics and Thermo-Mechanical Processes in the Steam Generators of NPP with VVER, Energoatomizdat, Moscow, Russia, 2001.

[2] “TRAC PF1/MOD2: theory manual," Tech. Rep., Los Alamos National Laboratory, Los Alamos, NM, USA, 1990.

[3] A. Bengaouer and D. Bestion, "CATHARE 2 V1.3. User's guide lines // Equipe CATHARE Centre d'Etudes Nucleaires de Grenoble," STR/LML/EM/94-266, 1995.

[4] RELAP5-3D Code Manual Volume 1: Code Structure, System Models, and Solutions Methods, Idaho National Laboratory, Idaho Falls, Idaho, USA, 2005.

[5] A. N. Veselovsky, A. F. Zivotyagin, S. D. Kalinichenko, A. E. Kroshilin, and V. E. Kroshilin, "The complex of the codes BAGIRA for simulation of the thermo-hydrodynamics of the multiphase media," Teploenergetika, no. 5, pp. 11-16, 1998 (Russian).

[6] A. N. Veselovsky, A. F. Zivotyagin, A. E. Kroshilin, and V. E. Kroshilin, "The full scale NPP simulators on the basis of the compex of the codes BAGIRA," Teploenergetika, no. 6, pp. 3844, 1999 (Russian).

[7] V. I. Melikhov, O. I. Melikhov, and B. I. Nigmatulin, "Thermalhydraulic analysis of horizontal steam generator," in Proceedings of the 1st International Symposium on Two-Phase Flow Modeling and Experimentation, vol. 1, pp. 511-518, Rome, Italy, October 1995.

[8] V. I. Melikhov, O. I. Melikhov, and T. V. Urban, "Mathematical simulation of the thermal hydraulic processes in the horizontal steam generator PGV-1000," Teploenergetika, vol. 49, no. 5, pp. 70-74, 2002 (Russian).

[9] Z. W. Stosic and V. D. Stevanovic, "Advanced threedimensional two-fluid porous media method for transient two-phase flow thermal-hydraulics in complex geometries," Numerical Heat Transfer, vol. 41, part B, pp. 263-289, 2002.

[10] R. I. Nigmatulin, Dynamics of the Multiphase Media. Part 1, Nauka, Moscow, Russia, 1987.

[11] O. I. Melikhov, N. B. Trunov, V. I. Melikhov, and Y. V. Parfenov, "Theoretical investigations for optimization of the arrangement of the tube bundles of the horizontal steam generators," in Proceedings of the 3rd Scientific and Technical Conference "Safety Assurance of NPP with WWER", p. 112, Book of Abstracts, Podolsk, Russia, May 2003.

[12] V. I. Melikhov, O. I. Melikhov, and I. V. Parfenov, "Mathematical modeling of thermal hydraulics in horizontal steam generator with STEG code," New in Russian Power Engineering, no. 8, pp. 21-33, 2008 (Russian).

[13] V. I. Melikhov, O. I. Melikhov et al., "Analysis of thermal hydraulics in horizontal steam generator with STEG code," in Proceedings of the 7th International Seminar on Horisontal Steam Generators, Podolsk, Russia, October 2006.

[14] A. I. Filchukov, Y. K. Sitnik, and N. B. Trunov, "A model to study the thermal hydraulics of horizontal steam generators and the principal tasks of the study," in Problems of the Nuclear Science and Industry, vol. 13 of NPP with VVER, pp. 61-68, Safety Assurance of NPP, Moscow, Russia, 2006.
[15] I. E. Idelchik, Hydraulic Resistance Reference Book, Mashinostroenie, Moscow, Russia, 1992.

[16] Z. R. Simovic, S. Ocokoljic, and V. D. Stevanovic, "Interfacial friction correlations for the two-phase flow across tube bundle," International Journal of Multiphase Flow, vol. 33, no. 2, pp. 217-226, 2007.

[17] M. Ishii and N. Zuber, "Drag coefficient and relative velocity in bubbly, droplet or particulate flows," AIChE Journal, vol. 25, no. 5, pp. 843-855, 1979.

[18] J. C. Rousseau and G. Houdayer, "Advanced safety code CATHARE summary of verification studies on separate effects experiments," in Proceedings of the 2nd International Topical Meeting on Nuclear Reactor Thermalhydraulics, pp. 343-351, Santa Barbara, Calif, USA, 1983. 

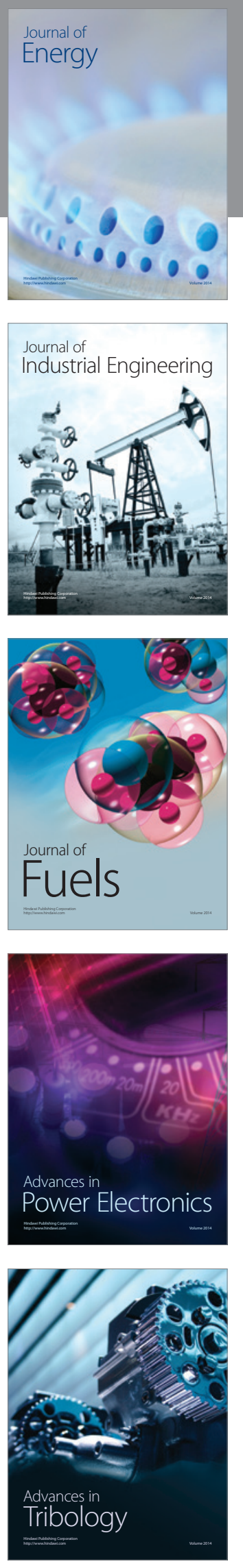
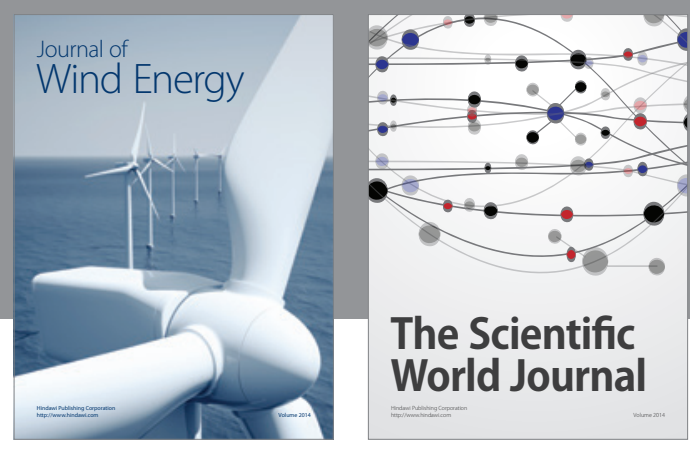

The Scientific World Journal

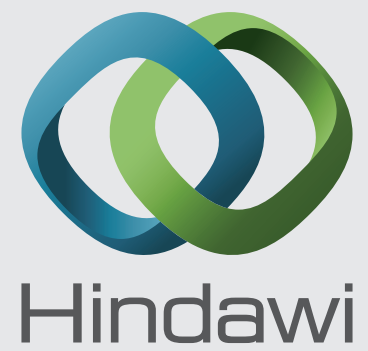

Submit your manuscripts at http://www.hindawi.com
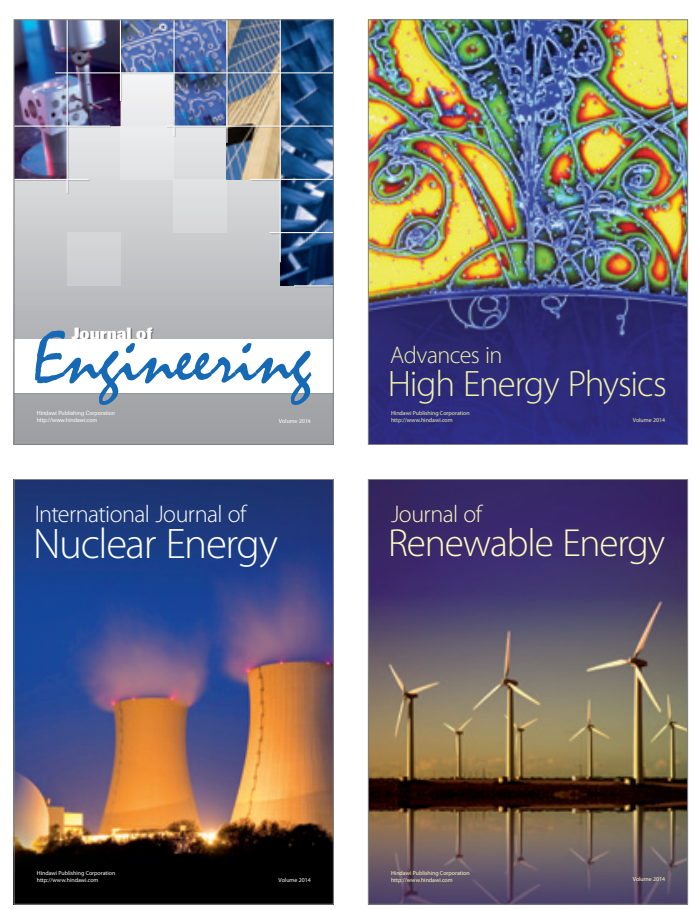

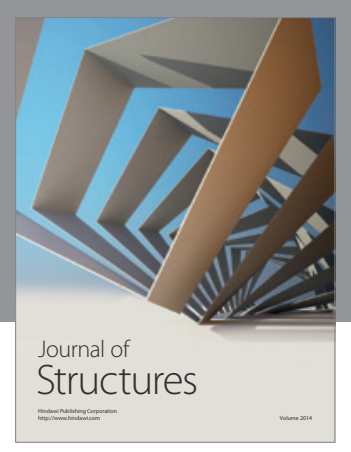

Rotating
Mechinery
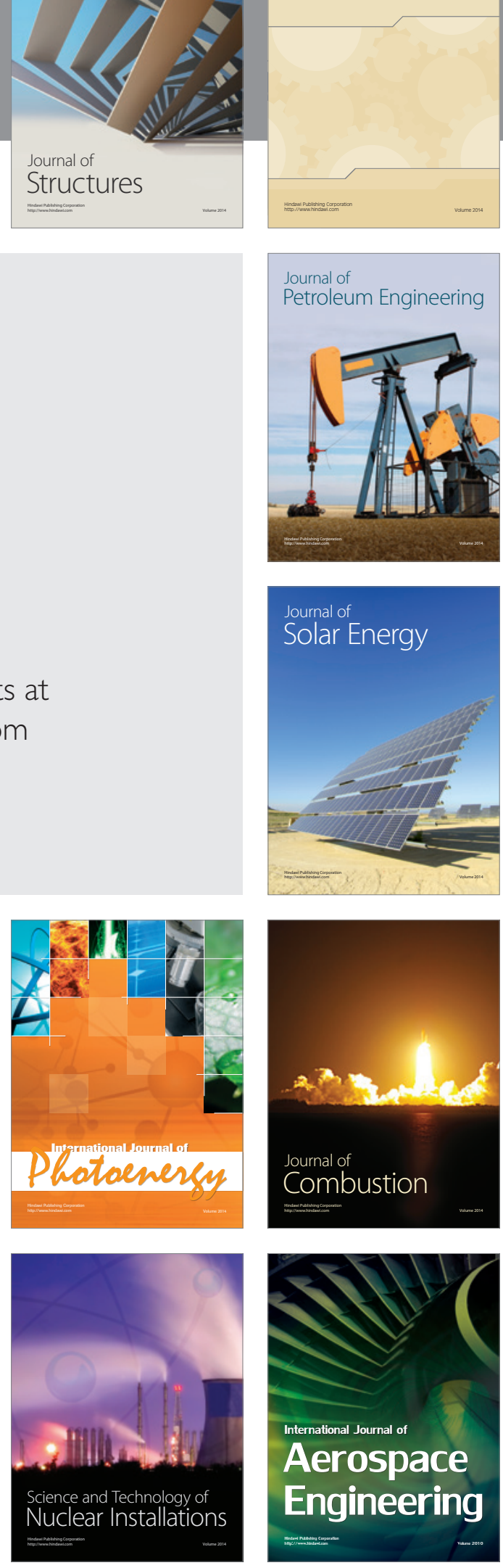